\title{
A SIMPLIFIED MODEL FOR PLOUGHING FORCES IN TURNING
}

\author{
Daniel J. Waldorf \\ Industrial and Manufacturing Engineering Department \\ Cal Poly State University \\ San Luis Obispo, CA
}

\section{KEYWORDS}

Machining, Forces, Edge Geometry, Ploughing

\begin{abstract}
This paper aims to provide experimental data in support of a modified theoretical model for quantifying the effect of cutting tool edge geometry on machining forces. A previously published slip-line model is simplified and extended to the case of turning. Several sets of machining experiments were run with customfabricated cutting inserts of varying edge hone radius and chamfer geometry. Cutting forces were measured using a dynamometer during cutting. Results show that varying edge geometry can have a major effect on cutting forces. The developed model effectively captures the edge phenomenon and its effect on cutting forces and also offers a glimpse of how the edge geometry can affect dynamic process damping.
\end{abstract}

\section{INTRODUCTION}

When a very sharp edge is used in machining, it is believed that the bulk of the forces exerted on the tool and workpiece are due to the shearing that takes place along the primary shear plane. Although the edge cannot be perfectly sharp, as long as the radius is less than about $.02 \mathrm{~mm}$ the contribution of edge ploughing to cutting forces is typically neglected and generally thought to be less than $5 \%$ of the total force. However, there are good reasons for having a larger hone on the edge: the edge is more resistant to chipping; it allows for different and thicker ceramic coatings on the tool; and it may help to dampen vibrations during cutting. Unfortunately, no generally accepted models exist for relating the size of the hone to the ploughing force components and little experimental data has been presented in the literature to suggest a reasonable relationship.

The ploughing mechanism has been studied for over forty years [Albrecht 1960, Palmer 1963] in attempts to explain various cutting phenomena such as the size effect of chip thickness on forces [Nakayama 1968], machined surface properties [Thiele 2000], burr formation [Lee 2002], and cutting process damping [Sisson 1969; Wu 1988; Elbestawi 1991; Ranganath 1999]. Ploughing has also been examined for its own contribution to cutting forces [Bitans 1965; Johnson 1967; AbdelMoneim 1974; Sarwar 1981; Rubenstein 
1990; Zhang 1991; Endres 1995; Wang 2002] and its relationship to worn tool flank forces [Usui 1984; Elanayar 1994].

Recently, several studies have been undertaken that deal explicitly with effects of cutting edge geometry. A new finite element model [Movahhedy 2002] of the machining process has been used to model the effect of a blunt or chamfered edge on cutting forces. The approach utilizes a combined Eulerian-Lagrangian model and a tool-work contact algorithm [Movahhedy 2000] for sliding-sticking friction conditions based on a relation [see Usui 1982] such as

$$
\tau_{\mathrm{f}}=\tau \cdot\left[1-\mathrm{e}^{-\mu \cdot \frac{\sigma}{\tau}}\right]
$$

where $\tau_{f}$ is the frictional stress, $\sigma$ is the normal stress, and $\tau$ is the shear flow stress. The authors assume $\mu=1$ based on experimental force measurements. Results compare measured forces with the FE simulation and also with an analytical model based on slip-line theory proposed in [Ren 2000]. A similar friction model is used in [Kim 1999] in a thermoviscoplastic Eulerian finite element model to predict the effects of increasing edge radius on cutting forces (and comparison to experiment). A model proposed in [Chang 1999] predicts the effect of a chamfered, rounded, or worn edge on the shear plane and, hence, cutting forces. The approach assumes a constant shear stress and uses geometry considerations to determine the shear plane size and orientation. Results are compared to experiments. Shatla [2000] utilized the Zorev friction law and commercial finite element software capable of automatic remeshing of high density local meshes to simulate the effects of honed and chamfered edges on cutting temperatures and stresses. Madhaven, et al, [2000] also utilize commercial software and employ a similar "shear-limited" friction model to simulate the indentation effects of the rounded cutting edge on stresses.

Several recent studies from the University of Michigan have also investigated edge effects in machining. Shimmel, et al [1997, 2000] performed an experimental study on edge radius variability and its effect on forces, followed by a slip-line based model [Manjunathaiah ASME 2000] that utilized an equivalent chamfer geometry for the rounded edge hone and slowspeed cutting experiments on brass. Another study [Manjunathaiah NAMRI 2000] compared a geometric model for predicting "average" rake angle to experimental tests with honed edges. Kountanya [2001] performed high-magnification experiments with edge-honed tools and then combined results [Endres 2002] to examine the edge's influence on forces and flank wear. Schimmel, et al, [2002] also examined the ploughing force components by applying the equivalent rake angle approach and accounting for a varying shear angle and shear stress for different ratios of uncut chip thickness to edge radius. These methods for force prediction suffer mainly from a large number of model parameters that are very difficult to determine without extensive experimentation.

In the current study, a two-dimensional slipline field for deformation below the cutting edge in orthogonal machining is modified and simplified so that the three-dimensional turning force components due to a rounded or chamfered cutting edge can be reasonably predicted knowing only the standard machining conditions, the size of the hone or chamfer, and the material shear stress. Experiments on two cutting materials are performed to validate the model.

\section{FORCE MODEL}

A slip-line field representing the deformation below a rounded cutting edge in orthogonal machining was presented by the author in [Waldorf 1998]. The model was based on a dead-metal zone formed at the rounded edge (see discussions in Palmer 1963, AbdelMoneim 1974, Sarwar 1981, Movaheddy 2000 and 2002, Kountanya 2001, and Ren 2000), a raised prow of material ahead of cutting, and a wedge of deformation below the dead-metal zone dependent on frictional stresses there. The basic slip-line field is shown in the Appendix and can be simplified by assuming a negligible prow $\left(\rho=0^{\circ}\right)$ and a friction stress on the dead-metal zone equal to the machining shear stress of the work material (i.e., $\tau_{\mathrm{f}}=\tau$ from Equation 1 ). Since the angle that slip-lines meet the dead-metal zone depends on this friction condition, the latter simplification implies that $\eta=0^{\circ}$ and the slip-line "field" collapses to a single slip line (i.e., $\delta=0$ ). The cutting (tangential) and thrust forces on the lower boundary of the dead-metal zone can then be written as: 


$$
\begin{aligned}
& \mathrm{F}_{\mathrm{C}}^{\prime \prime}=\tau \cdot \mathrm{w} \cdot \mathrm{r}_{\mathrm{e}} \cdot \tan \left(\frac{\pi}{4}+\frac{\alpha}{2}\right) \\
& \mathrm{F}_{\mathrm{T}}^{\prime \prime}=\tau \cdot \mathrm{w} \cdot\left(1+\frac{\pi}{2}\right) \cdot \mathrm{r}_{\mathrm{e}} \cdot \tan \left(\frac{\pi}{4}+\frac{\alpha}{2}\right)
\end{aligned}
$$

where $w$ is the cutting width, $r_{e}$ is the edge radius, $\alpha$ is the rake angle, and $\tau$ is the machining shear stress determined from measured cutting forces during orthogonal or oblique cutting and using the standard Merchant equations as found in Shaw [1984].

The orthogonal width of cut $w$ in Equation (2) can be replaced with the cutting edge length

$$
\mathrm{w}=\mathrm{r}_{\mathrm{n}}\left(\frac{\pi}{2}-\gamma_{\mathrm{L}}+\sin ^{-1}\left(\frac{\mathrm{f}}{2 \cdot \mathrm{r}_{\mathrm{n}}}\right)\right)+\frac{\mathrm{d}-\mathrm{r}_{\mathrm{n}}\left(1-\sin \left(\gamma_{\mathrm{L}}\right)\right)}{\cos \left(\gamma_{\mathrm{L}}\right)}
$$

for a standard turning operation, where $r_{n}$ is the tool nose radius, $\gamma_{L}$ is the side cutting edge (lead) angle, $f$ is the nominal feed per rev, and $d$ is the nominal depth of cut. However, because of the curved nature of the cutting edge when turning with a nose and the tendency for some of the forces near the nose to cancel, the thrust force vectors should be applied to differential elements along the cutting edge and summed before resolving the force into the longitudinal direction as $\mathrm{F}^{\prime \prime} \mathrm{z}$. The thrust forces for ploughing in Equation (2) can be rewritten as

$$
\mathrm{F}_{\mathrm{T}}^{\prime \prime}=\mathrm{K}_{\mathrm{p}} \cdot \mathrm{w}
$$

where

$$
\mathrm{K}_{\mathrm{p}}=\tau \cdot\left(1+\frac{\pi}{2}\right) \cdot \mathrm{r}_{\mathrm{e}} \cdot \tan \left(\frac{\pi}{4}+\frac{\alpha}{2}\right)
$$

The longitudinal ploughing force is then

$$
\mathrm{F}_{\mathrm{Z}}^{\prime \prime}=\int_{0}^{\mathrm{w}} \mathrm{K}_{\mathrm{P}} \cdot \cos \gamma(\ell) \cdot \mathrm{d} \ell
$$

where $\ell$ represents the length of the cutting edge from 0 to $\mathrm{w}$ as defined in Equation (3) and $\gamma(\ell)$ is the varying side cutting edge angle along the curving cutting edge. Radial forces can be found in a similar fashion using $\sin \gamma(\ell)$ but are not included here. Also, in turning, the rake angle $\alpha$ is replaced with the "normal" rake angle

$$
\alpha=\tan ^{-1}\left[\left(\tan \left(\alpha_{\mathrm{s}}\right) \cos \left(\gamma_{\mathrm{eL}}\right)+\tan \left(\alpha_{\mathrm{b}}\right) \sin \left(\gamma_{\mathrm{eL}}\right)\right) \cos (\mathrm{i})\right]
$$

where $\mathrm{i}$ is the inclination angle given by

$$
\mathrm{i}=\tan ^{-1}\left(\tan \left(\alpha_{\mathrm{b}}\right) \cos \left(\gamma_{\mathrm{eL}}\right)-\tan \left(\alpha_{\mathrm{S}}\right) \sin \left(\gamma_{\mathrm{eL}}\right)\right),
$$

$\alpha_{s}$ and $\alpha_{b}$ are the side and back rake angles, and $\gamma_{\mathrm{eL}}$ is the effective lead angle given by

$$
\gamma_{e L}=\tan ^{-1}\left[\tan \left(\gamma_{L}\right)+\frac{\left(r_{n}+\frac{f}{2}\right)}{d}\left(\frac{1-\sin \left(\gamma_{L}\right)}{\cos \left(\gamma_{L}\right)}\right)\right] .
$$

A chamfered edge can be accommodated in Equation (2) by simply using an equivalent edge radius. For a chamfer of width $T$ at angle $\lambda$, an equivalent edge radius would average the two "legs" of the chamfer, i.e., $T \cos (\lambda)$ and $T \sin (\lambda)$.

\section{EXPERIMENTATION}

Two sets of interrupted turning experiments were completed. The first set was with 4340 steel and the second was with 6061-T6 aluminum. Both were run on a $15 \mathrm{HP}(11,200$ W) Gisholt turret lathe. A Kistler dynamometer (mounted below the tool) was used to collect cutting forces in the tangential and longitudinal (feed) directions, though radial forces were also collected for select tests. The cutting tools (Kennametal KC850 for steel and KC730 for aluminum) were specially ground by Kennametal to have the edge profiles shown in Figure 1.

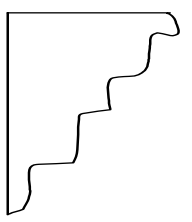

(A)

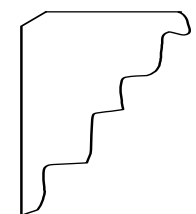

(B )

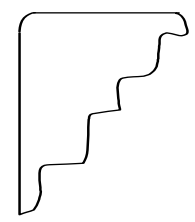

(C)
FIGURE 1. EDGE PREP CONDITIONS: (A) "UPSHARP" (B) T-LAND $\left(.102 \mathrm{~mm} \times 20^{\circ}\right)$, AND (C) CIRCULAR HONE.

For the KC850 on steel, the edges were: Upsharp ( $\approx .05 \mathrm{~mm}$ radius), Honed (.13 $\mathrm{mm}$ hone), 
and T-land. For the KC730 on aluminum, the edges were: Up-sharp ( $\approx .003 \mathrm{~mm}$ radius), Small Hone (.013 $\mathrm{mm}$ hone), Large Hone $(.05 \mathrm{~mm}$ hone), and T-land. All inserts (TNG-432) were held in negative rake (MTGNR 16-4-D) holders. Cutting conditions varied as shown in Table 1.

TABLE 1. TESTING CONDITIONS FOR TURNING.

\begin{tabular}{|l|c|c|c|c|}
\hline $\begin{array}{l}\text { Test } \\
\text { Set }\end{array}$ & $\begin{array}{c}\text { Feed } \\
(\mathrm{mmpr})\end{array}$ & $\begin{array}{c}\text { Speed } \\
(\mathrm{m} / \mathrm{min})\end{array}$ & RPM & $\begin{array}{c}\text { Depth } \\
(\mathrm{mm})\end{array}$ \\
\hline $\begin{array}{l}4340 \\
\text { Steel }\end{array}$ & $.102-.229$ & $140-245$ & $530-$ & 2.03 \\
& & & 880 & \\
\hline $6061-$ & $.076-.152$ & $245-420$ & $880-$ & 5.08 \\
T6 Al & & & 1500 & \\
\hline
\end{tabular}

A data collection system based on LabView@ software and National Instruments signal processing hardware was developed and used to collect the force signals.

A corresponding set of oblique tube-cutting experiments was performed for each work material in order to obtain a value for the machining shear stress at the approximate conditions of the turning tests. In these tests, a tube was cut without using the tool nose radius. Inclination angle was held at $5^{\circ}$. All three components of the cutting force (i.e., tangential, longitudinal, and radial) were collected for these tests using the dynamometer. Chips were collected and measured to determine the shear angle in the usual way (see [Shaw 1984]).

\section{RESULTS}

Initial results show that the effect of hone on cutting forces is quite evident. For example, in 4340 steel at low speed and low feed conditions, the average steady-state tangential force increased slightly from $625 \mathrm{~N}$ to $700 \mathrm{~N}$ as edge radius increased from $.05 \mathrm{~mm}$ to $.13 \mathrm{~mm}$. The longitudinal force, however, rose dramatically from $450 \mathrm{~N}$ to $700 \mathrm{~N}$. A similar \% increase was seen in the radial force $(190 \mathrm{~N}$ to $275 \mathrm{~N})$. The thrust (longitudinal/radial) component of force is thus typically affected more by edge hone than is the tangential. It is because of this effect that it is thought that cutting process damping increases as edge hone increases, since the ploughing component of the thrust force acts against the vibrating motion of the tool (assuming vibration in the feed/longitudinal direction). Overall trends for the steel workpieces are shown in Figure 2 and 3 below.

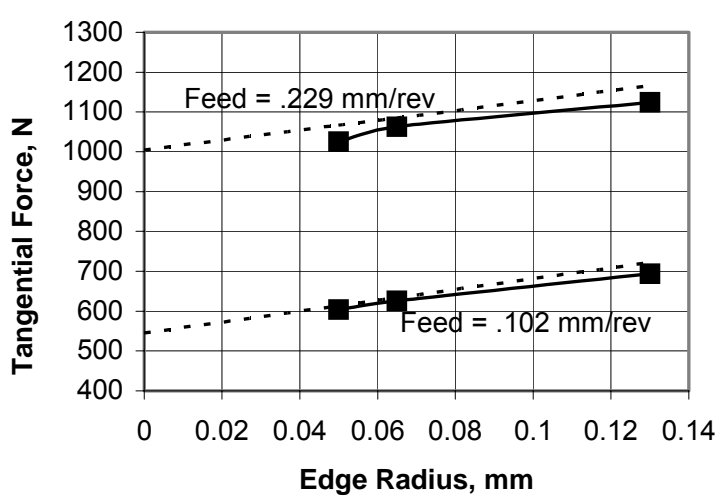

FIGURE 2. EFFECT OF EDGE RADIUS ON TANGENTIAL FORCES IN STEEL.

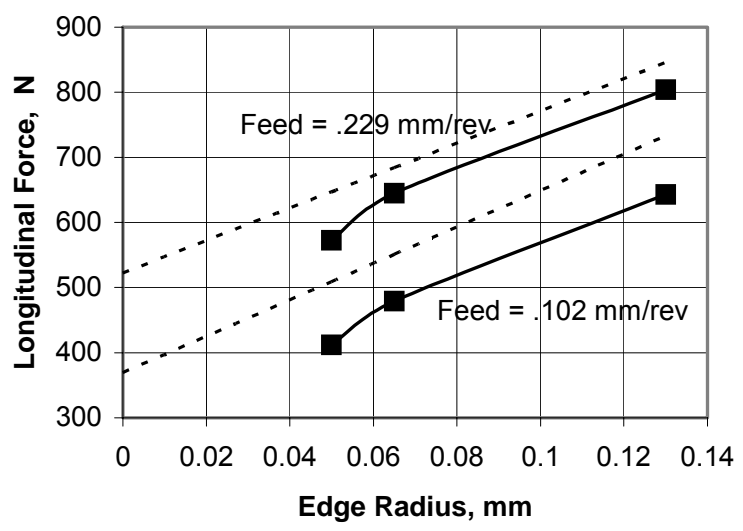

FIGURE 3. EFFECT OF EDGE RADIUS ON LONGITUDINAL FORCES IN STEEL.

In these figures, each data point (connected by solid lines) represents the average of four independent cutting tests, two replicates for each of two cutting speeds. Since speed had a negligible effect on forces, the results were combined for clarity. In steel, tangential forces rose by $95 \mathrm{~N}(11 \%)$ on average as the edge radius increased from $.05 \mathrm{~mm}$ (up-sharp) to .13 $\mathrm{mm}$ (honed). The T-land results are shown for an equivalent edge radius of $.065 \mathrm{~mm}$. This number is the average of the two "legs" of the chamfer; i.e., $.102 \sin \left(20^{\circ}\right)$ and $.102 \cos \left(20^{\circ}\right)$ $\mathrm{mm}$. Over the same range, longitudinal forces increased by $231 \mathrm{~N}(47 \%)$ on average. In both cases, increasing feed rate had a pronounced but consistent effect of increasing forces, while varying cutting velocity had no significant effect. Since the force curves are essentially parallel between the low feed rate and high feed rate tests, it suggests that the absolute increase in forces due to an increased feed is independent 
of cutting edge radius, or that ploughing force components do not depend on feed.

Predicted forces based on the modified slipline theory presented above are shown as dashed lines. The predicted force increases due to increasing edge radius are remarkably similar to the observed results. The predictions are based on a machining shear stress of 569 $\mathrm{N} / \mathrm{mm}^{2}$, found from the oblique tube-turning tests utilizing an up-sharp KC730 cutting insert.

The predicted sharp tool forces (i.e., shearing only) were estimated by first computing forces along and normal to the shear plane

$$
\begin{aligned}
& \mathrm{F}_{\mathrm{S}}^{\prime}=\tau \cdot \frac{\mathrm{w} \cdot \mathrm{f}}{\sin (\phi) \cdot \cos (\mathrm{i})} \\
& \mathrm{F}_{\mathrm{N}}^{\prime}=\sigma \cdot \frac{\mathrm{w} \cdot \mathrm{f}}{\sin (\phi) \cdot \cos (\mathrm{i})}
\end{aligned}
$$

where the shear stress $\tau$, the normal stress $\sigma$, and the shear angle $\phi$ were all estimated from the oblique tube-turning tests run at the same conditions. Cutting and thrust forces are

$$
\begin{aligned}
& \mathrm{F}_{\mathrm{C}}^{\prime}=\mathrm{F}_{\mathrm{S}}^{\prime} \cdot \cos (\phi)+\mathrm{F}_{\mathrm{N}}^{\prime} \cdot \sin (\phi) \\
& \mathrm{F}_{\mathrm{T}}^{\prime}=\mathrm{F}_{\mathrm{N}}^{\prime} \cdot \cos (\phi)-\mathrm{F}_{\mathrm{S}}^{\prime} \cdot \sin (\phi)
\end{aligned}
$$

As with the ploughing components above, the thrust force can be resolved into the longitudinal direction by first rewriting the thrust force as

$$
\mathrm{F}_{\mathrm{T}}^{\prime}=\mathrm{K}_{\mathrm{T}} \cdot \mathrm{w} \cdot \mathrm{f}
$$

where

$$
\mathrm{K}_{\mathrm{T}}=\left(\frac{\sigma \cdot \mathrm{f} \cdot \cos (\phi)}{\sin (\phi) \cdot \cos (\mathrm{i})}\right)-\left(\frac{\tau \cdot \mathrm{f} \cdot \sin (\phi)}{\sin (\phi) \cdot \cos (\mathrm{i})}\right) .
$$

The longitudinal shear force is then given by

$$
\mathrm{F}_{\mathrm{Z}}^{\prime}=\int_{0}^{\mathrm{w}} \mathrm{K}_{\mathrm{T}} \cdot \mathrm{f} \cdot \cos \gamma(\ell) \cdot \mathrm{d} \ell
$$

As seen in Figures 4 and 5 , in aluminum (shear stress $316 \mathrm{~N} / \mathrm{mm}^{2}$ ) tangential forces rose by $38 \mathrm{~N}(6 \%)$ on average as the edge radius increased from $.003 \mathrm{~mm}$ (up-sharp) to $.05 \mathrm{~mm}$ (large hone) while longitudinal forces increased by $199 \mathrm{~N}(55 \%)$. T-land results are again shown with $.065 \mathrm{~mm}$ equivalent edge radius, though results are not as consistent as with steel. Again, increasing feed had a consistent effect of increasing forces.

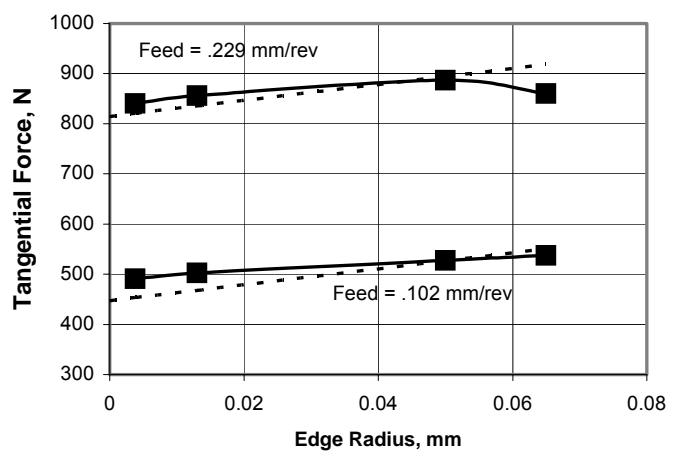

FIGURE 4. EFFECT OF EDGE RADIUS ON TANGENTIAL FORCES IN ALUMINUM.

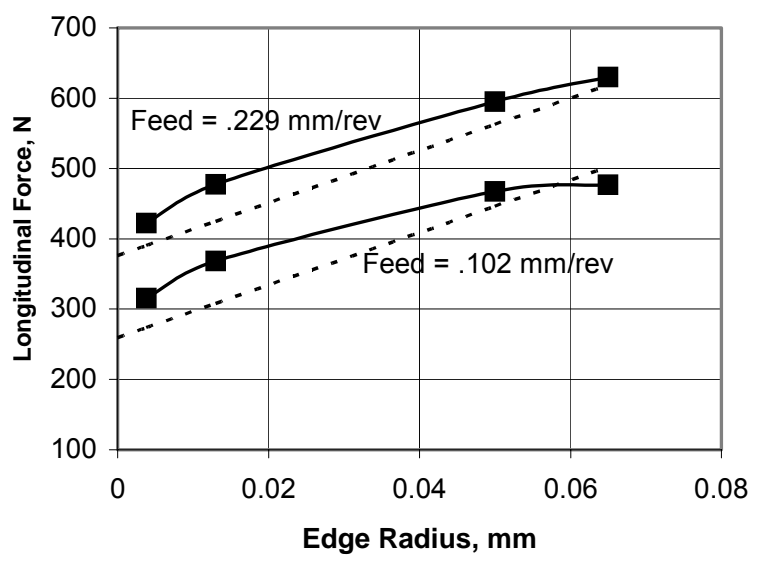

FIGURE 5. EFFECT OF EDGE RADIUS ON LONGITUDINAL FORCES IN ALUMINUM.

The small errors in the predicted forces are readily explained by the simplifications inherent in the model. The absolute error between model and measured forces is likely due to assumption of constant shear stress and/or the idealized slip-line factor $(1+\pi / 2)$ in Equation (5). Each of the experimental curves in Figures 2 through 5 also suggests some non-linearity not captured in the model. This may be due to increasing static deflection (and corresponding decrease in depth and feed) of the tool and workpiece as the forces increase. It could also be the result of increasing (though still small) sidespread of material (i.e, a burr) as the edge hone increases.

\section{Effect of Ploughing on Process Damping}

Although the effect of ploughing on process damping is present in normal turning, it is most 
easily demonstrated by considering orthogonal tube cutting in which the thrust force is entirely in the longitudinal $Z$ direction. In that case, based on Equations (4) and (12) the time-varying dynamic longitudinal cutting force is

$$
\mathrm{F}_{\mathrm{Z}}(\mathrm{t})=\mathrm{K}_{\mathrm{T}} \cdot \mathrm{w} \cdot(\mathrm{f}-\mathrm{Z}(\mathrm{t}))+\mathrm{K}_{\mathrm{p}} \cdot \mathrm{w}
$$

where the feed rate has been modified to account for tool position $\mathrm{Z}(\mathrm{t})$ as it vibrates away from (or into) the part.

From Equation (5) the ploughing coefficient $\mathrm{K}_{\mathrm{p}}$ depends on the rake angle $\alpha$. Since the rake angle is the angle between the rake face and a normal to the instantaneous velocity (i.e., $\mathrm{V}$ modified by $\dot{Z}(\mathrm{t}))$, alpha is defined as

$$
\alpha=\alpha_{0}-\tan ^{-1}\left(\frac{\dot{\mathrm{Z}}(\mathrm{t})}{\mathrm{V}}\right)
$$

where $\alpha_{0}$ is the nominal "normal" rake angle. Using a first-order Taylor series approximation about $\alpha=\alpha_{0}$, the tangent term can be written

$$
\tan \left(\frac{\pi}{4}+\frac{\alpha}{2}\right)=\tan \left(\frac{\pi}{4}+\frac{\alpha_{0}}{2}\right)-\frac{0.5 / \mathrm{V}}{\cos ^{2}\left(\frac{\pi}{4}+\frac{\alpha_{0}}{2}\right)} \cdot \dot{\mathrm{Z}}(\mathrm{t}) \text {. }
$$

Therefore, the ploughing force component depends on the vibration velocity $\dot{Z}(\mathrm{t})$ and, hence, it affects the process damping. The equations suggest that increasing edge radius $r_{e}$ (see Equation (5)) increases the damping ratio based on the signs of the coefficients in Equation (17). However, a more through analytical and experimental study is needed to demonstrate the effect.

\section{CONCLUSIONS}

A slip-line model for ploughing in orthogonal cutting has been modified and extended to the case of three-dimensional turning. Besides the edge radius and the cutting geometry, only the machining shear stress is used in the model. The model was used to predict the increase in cutting forces due to various edge hones and chamfers. A comparison to experiments run on 4340 steel and 6061-T6 aluminum showed that the model does an excellent job of capturing the increase in forces due to the edge. Equations are also presented to show how the ploughing force model can be used to quantify the effect of ploughing on dynamic damping in the process.

The author would like to express his appreciation to the SME Education Foundation and to Cal Poly for providing funds, equipment, and assistance in support of this research.

\section{APPENDIX}

The slip-line field for the ploughing mechanism presented in [Waldorf 1998] is reproduced in figure A1 below with minor modifications. The field includes three regions of rigid material motion: a 45-45-90 triangle that meets the free surface (I), a rectangle adjacent to the shear plane (II), and a right triangle adjacent to the shaded dead-metal zone below the cutting edge (III). Two wedge-shaped "fan" fields, in which non-uniform deformation occurs, join the rigid sections. Three angles define field geometry:

1. The prow angle $\rho$, allowing for material to raise up due to compressive stresses prior to reaching the shear plane (noted as $A B$ );

2. The traditional shear plane angle $\phi$ that governs the orientation of the shear plane $A B$. It is on $A B$ that the primary shearing (velocity discontinuity) takes place; and

3. The angle $\eta$ of the triangular section below the dead metal zone attached to the rounded edge. This angle is governed by the friction conditions at the work-dead zone interface CA. It is determined from the relationship between the frictional stress at the interface $\tau_{f}$ and the bulk shear stress $\tau$, i.e., $\tau_{f}=m^{*} \tau$, where $\eta=.5^{*} \cos ^{-1}(m)$.

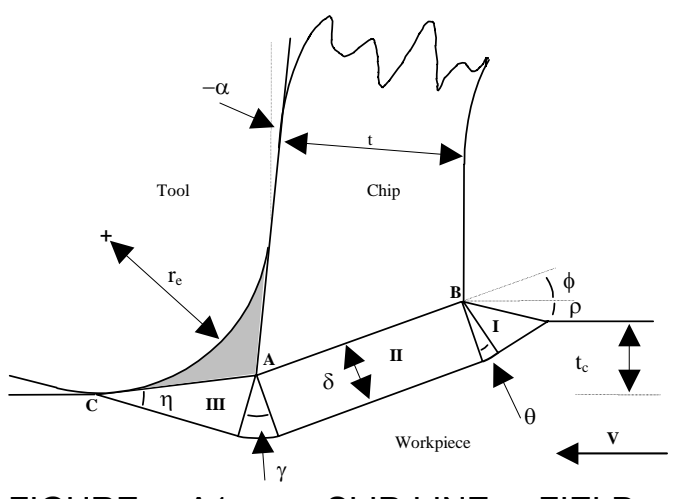

FIGURE A1 SLIP-LINE FIELD FOR PLOUGHING (FROM [WALDORF 1998]). 
To ensure consistent velocity conditions, the fan field angles $\theta$ and $\gamma$ are dependent on the previously defined angles according to

$$
\theta=\frac{\pi}{4}-\rho-\phi
$$

and

$$
\gamma=\eta+\phi-\sin ^{-1}(\sqrt{2} \cdot \sin (\rho) \cdot \sin (\eta)) \cdot
$$

The width $\delta$ of the rectangle also depends on other quantities, including the nominal tool rake angle $\alpha_{0}$, according to

$$
\frac{\delta}{\sin (\eta)}=\sqrt{\left(\begin{array}{l}
\left.\mathrm{r}_{\mathrm{e}} \cdot \tan \left(\frac{\pi}{4}+\frac{\alpha_{0}}{2}\right)+\frac{\sqrt{2} \cdot \delta \cdot \sin (\rho)}{\tan \left(\frac{\pi}{2}+\alpha_{0}\right)}\right)^{2} \\
+2 \cdot[\delta \cdot \sin (\rho)]^{2}
\end{array}\right.}
$$

A hodograph (Figure A2) can also be constructed to illustrate the velocity distribution throughout the slip-line field.

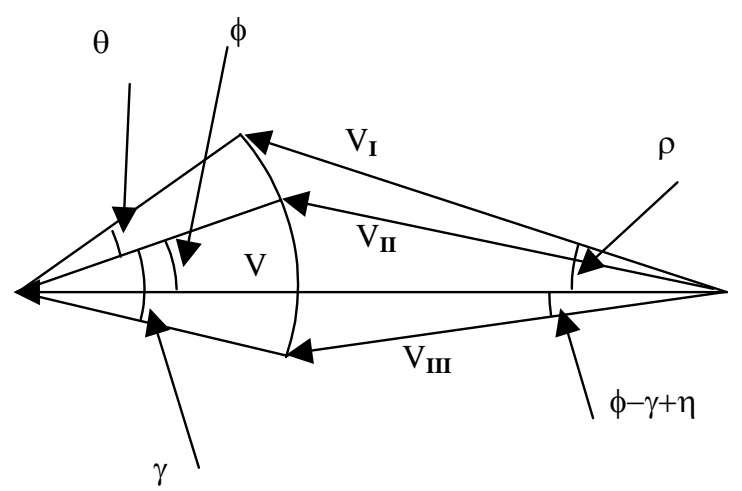

FIGURE A2 VELOCITY HODOGRAPH.

In the hodograph, the main cutting velocity $\mathrm{V}$ is shown as a horizontal line, while the velocities in the three rigid regions are indicated by arrows.

\section{REFERENCES}

AbdelMoneim, M. Es. and R.F. Scrutton, (1973), "The Tribology of Cutting Tools during Finish Machining. I and II, Wear, Vol. 25, pp. 45-63.

Albrecht, P., (1960), "New Developments in the Theory of the Metal-Cutting Process, Part 1. The Ploughing Process in Metal Cutting," Trans. ASME J. of Eng. for Industry, Nov., pp. 348-357.
Bitans, K. and R.H. Brown, (1965), "An Investigation of the Deformation in Orthogonal Cutting," Int. J. Machine Tool Design and Research, Vol. 5, pp. 155-165.

Chang, C.-S., (1999), "A Study of Cutting Forces for Milling Plain Carbon Steel Using Chamfered Main Cutting Edge Tools," ASME MED-Vol. 10, Mfg. Science and Engineering, pp. 243-252.

Elanayar V.T., Sunil and Yung C. Shin, (1994), "Modeling of Tool Forces for Worn Tools: Flank Wear Effects," Materials Issues in Machining-II, Proc. Winter Annual Meeting ASME, pp. 341-61.

Elbestawi, M.A., Ismail, F., Du, R., and B.C. Ullagaddi, (1991), "Modelling Machining Dynamics Including Damping in the ToolWorkpiece Interface," ASME PED-Vol. 54/TribVol. 2, Tribological Aspects in Mfg., pp. 253-264.

Endres, W., DeVor, R., and S. Kapoor, (1995), "A Dual-Mechanism Approach to the Prediction of Machining Forces, Parts 1 and 2," Trans. ASME, J. of Engineering for Industry, Vol. 117, Nov., pp. 526-541.

Endres, W.J. and R.K. Kountanya, (2002), "The Effects of Corner Radius and Edge Radius on Tool Flank Wear," Trans of NAMRI/SME, Vol. 30, pp. 401-407.

Johnson, W., (1967), "Cutting with Tools having a Rounded Edge: Some Theoretical Considerations," Annals of the CIRP, Vol. 14, pp. 315-19.

Kim, K.W., Lee, W.Y., and H.C. Sin, (1999), "A Finite-Element Analysis of Machining With the Tool Edge Considered," J. of Materials Processing Technology, Vol. 86, pp. 45-55.

Kountanya, R.K. and W.J. Endres, (2001), "A High-Magnification Experimental Study of Orthogonal Cutting with Edge-Honed Tools," ASME MED-Vol. 12, pp. 157-163.

Lee, K. and D.A. Dornfeld, (2002), "An Experimental Study on Burr Formation in Micro Milling Aluminum and Copper," Trans. of NAMRI/SME, Vol. 30, pp. 255-262.

Madhaven, V., Chandrasekar, S., and T.N. Farris, (2000), "Machining as a Wedge Indentation," ASME Journal of Applied Mechanics, Vol. 67, pp. 128-139. 
Manjunathaiah, J. and W.J. Endres, (2000), "A Study of Apparent Negative Rake Angle and Its Effects on Shear Angle During Orthogonal Cutting With Edge-Radiused Tools," Trans. of NAMRI /SME, Vol. 28, pp. 197-202.

Manjunathaiah, J. and W.J. Endres, (2000), "A New Model and Analysis of Orthogonal Machining With an Edge-Radiused Tool," ASME J. of Mfg. Science and Eng., V. 122, pp. 384-90.

Movahhedy, M.R., Gadala, M.S., and Y. Altintas, (2000), "Simulation of the Orthogonal Metal Cutting Process Using an Arbitrary LagrangianEulerian Finite-Element Method," J. of Materials Processing Technology, Vol. 103, pp. 267-275.

Movahhedy, M.R., Altintas, Y., and M.S. Gadala, (2002), "Numerical Analysis of Metal Cutting With Chamfered and Blunt Tools," ASME J. of Mfg. Science and Eng., Vol. 124, pp. 178-88.

Nakayama, K. and K. Tamura, (1968), "Size Effect in Metal-Cutting Force," Trans. ASME, J. of Engineering for Industry, Feb., pp. 119-126.

Palmer, W. and R. Yeo, (1963), "Metal Flow Near the Tool Point during Orthogonal Cutting with a Blunt Tool," Proc. 4th Int. MTDR, p 61-71.

Ranganath, S., Narayanan, K, and J. Sutherland (1999), "The Role of Flank Face Interference in Improving the Accuracy of Dynamic Force Predictions in Peripheral Milling," ASME J. of Mfg. Science and Eng., Vol. 121, pp. 593-99.

Ren, H. and Y. Altintas, (2000), "Mechanics of Machining With Chamfered Tools," ASME J. of Mfg. Science and Eng., Vol. 122, pp. 650-59.

Rubenstein, C., (1990), "The Edge Force Components in Oblique Cutting," Int J. Machine Tools and Mfr., Vol. 30, No. 1, pp. 141-149.

Sarwar, M. and P.J. Thompson, (1981), "Cutting Action of Blunt Tools," Proc. 22nd Int. MTDR Conf., pp. 295-304.

Shimmel, R.J., Manjunathaiah, J., and W.J. Endres, (1997), "An Experimental Investigation of the Variability of Edge Hones and their Effects on Machining Forces," ASME MED-Vol. 6-2, Mfg Science and Technology, pp. 261-267.

Schimmel, R.J., Manjunathaiah, J., and W.J. Endres, (2000), "Edge Radius Variability and
Force Measurement Considerations," ASME J. of Mfg. Science and Eng., Vol. 122, pp. 590-93.

Schimmel, R., Endres, W., and R. Stevenson, (2002), "Application of an Internally Consistent Material Model to Determine the Effect of Tool Edge Geometry in Orthogonal Machining," ASME J. of Mfg. Science and Eng., V. 124, pp. $536-43$.

Shatla, M., Yen, Y.-C., and T. Altan, (2000), "Tool-Workpiece Interface in Orthogonal Cutting - Application of FEM Modeling," Trans. of NAMRI/SME, Vol. 28, pp. 173-178.

Shaw, M.C., (1984), Metal Cutting Principles, Clarendon Press.

Sisson, T.R. and R.L. Kegg, (1969), "An Explanation of Low-Speed Chatter Effects," Trans. ASME, J. of Eng. for Industry, Nov. pp. 951-58.

Thiele, J.D., et al, (2000), "Effect of CuttingEdge Geometry and Workpiece Hardness on Surface Residual Stresses in Finish Hard Turning of AISI 52100 Steel," ASME J. of Mfg. Science and Engineering, Vol. 122, pp. 642-49.

Usui, E. and T. Shirakashi, (1982), "Mechanics of Machining from Descriptive to Prescriptive Theory," ASME PED-Vol. 7, On the Art of Cutting Metals - 75 Years Later, pp. 13-35.

Usui, E., Shirakashi, T., and T. Kitagawa, (1984), "Analytical Prediction of Cutting Tool Wear," Wear, v. 100, pp. 129-151.

Waldorf, D.J., DeVor, R.E., and S.G. Kapoor, (1998), "A Slip-Line Field for Ploughing During Orthogonal Cutting," ASME J. of Mfg. Science and Engineering, Vol. 120, No. 4, pp. 693-699.

Wang, J.-J. J. and C.M. Zheng, (2002), "An Analytical Force Model With Shearing and Ploughing Mechanisms for End Milling," Int. J. of Machine Tools Mfr., Vol. 42, No. 7, pp. 761-71.

Wu, D.W., (1988), "Application of a Comprehensive Dynamic Cutting Force Model to Orthogonal Wave-generating Processes," Int J. Mech. Science, Vol. 30, No. 8, pp. 581-600.

Zhang, H., Liu, P., and R. Hu, (1991), "A Threezone Model and Solution of Shear Angle in Orthogonal Machining," Wear, V. 143, pp. 29-43. 